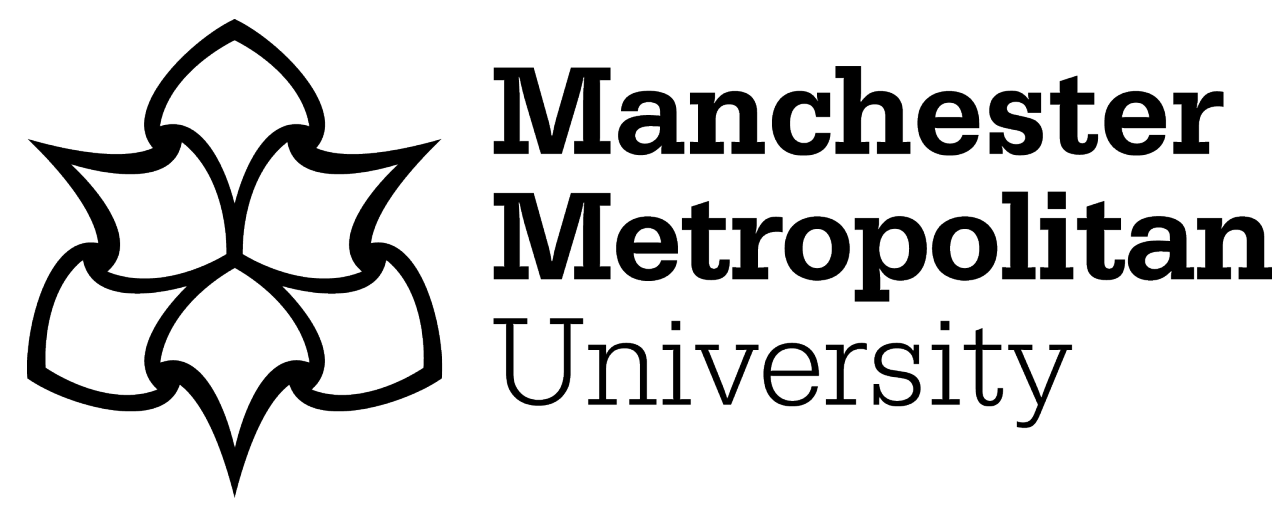

Ahmed, A ORCID logoORCID: https://orcid.org/0000-0002-61640656, Madoc-Jones, I, Gibbons, A, Jones, K ORCID logoORCID: https://orcid.org/0000-0002-8090-4557, Rogers, M and Wilding, M (2019) Challenges to Implementing the New Homelessness Prevention Agenda in Wales. Social Policy and Society, 19 (1). pp. 157-169. ISSN 1474-7464

Downloaded from: https://e-space.mmu.ac.uk/625884/

Version: Accepted Version

Publisher: Cambridge University Press

DOI: https://doi.org/10.1017/S147474641900040X

Please cite the published version 


\title{
Challenges to Implementing the New Homelessness Prevention Agenda in Wales
}

\author{
Anya Ahmed*, Iolo Madoc-Jon es**, An drea G ibbons ${ }^{* * *}$, Katy \\ Jones ${ }^{\dagger}$, \\ Michaela Roger $s^{\ddagger}$ and Mark Wilding $\$$ \\ *University of Salford \\ E-mail: A.Ahmed@salford.ac.uk \\ **Wrexham Glyndîr University \\ E-mail: i.m.jones@glyndwr.ac.uk \\ *** University of Salford \\ E-mail: A.R.Gibbons1@salford.ac.uk \\ ${ }^{\dagger}$ Manchester Metropolitan University \\ E-mail: katy.jones@mmu.ac.uk \\ FUniversity of Sheffield \\ E-mail: m.rogers@sheffield.ac.uk \\ SUniversity of Salford \\ E-mail: M.A.Wilding@salford.ac.uk
}

Devolution presented an opportunity for the Welsh Government to introduce changes to housing and homelessness policy, and the subsequent homelessness reforms are seen as one of the best examples to date of the Welsh Government using its powers. However, devolved governments in small countries face a number of challenges in terms of realising their housing policy ambitions. In this article we argue that there is inevitable dissonance between the policy behind the Welsh Government legislation (prevention) and practice (implementation) associated with structural challenges (for example, austerity and budget restrictions, Welfare Reform and the availability of affordable accommodation). In response we propose a number of actions the Welsh Government might undertake to attempt to mitigate such structural challenges which also resonate in the English context where welfare retrenchment and homelessness prevention policies operate simultaneously.

Keywords: Homelessness prevention, the Housing Act (Wales) 2014.

\section{Introduction}

It is widely acknowledged that homelessness is a complex and multi-faceted phenomenon which is contested and politically and morally charged (Somerville, 2013; Farrugia and Gerrard, 2016). A 'new orthodoxy' of homelessness research (encompassing 'sin talk', 'sick talk', and 'system talk') has explored the link between homelessness and individual culpability or incapacity and structural inequality (see, for example, Neale, 1997; Pleace, 2000; Fitzpatrick, 2005; Somerville, 2013). Structural causes include poverty and unemployment, a shortage of available and affordable housing, the effects of recession, and limits to benefit payments and displacement. Individual causes include relationship 
breakdown, mental health issues, alcohol and substance misuse, being in prison, and traumatic individual events.

In 1999 the UK Government devolved responsibility for a range of policy areas including housing and homelessness - to the National Assembly for Wales. In 2011, primary law-making powers were passed to the Welsh Government, allowing constitutional changes to be made in respect of the devolved policy areas. The Welsh model provides the first example of homelessness services being systematically reviewed since the preventative turn (Mackie, 2015). Part 2 of the Housing Act (Wales) 2014 (hereafter The Act) aimed to ensure that assistance is available for everyone who is at risk of homelessness or is homeless and that early interventions should take place to prevent crises. The most important change includes new duties for local authorities to help prevent homelessness for anyone who asks for help and the duty that authorities take 'reasonable steps' to prevent or relieve homelessness (see the review article in this themed section for a detailed discussion of the legislation: Ahmed and Madoc-Jones, 2019).

In this article we argue that there is inevitable dissonance between the policy behind the Welsh Government legislation (prevention) and practice (implementation) due to the effects of structural challenges (for example, austerity and budget restrictions, Welfare Reform and availability of affordable accommodation). The article is structured in the following way: first, we provide an overview of homelessness policy and prevention in an international context; second, we introduce the Welsh legislation and place it within the context of UK homelessness law and policy; third, the methodology underpinning the study from which data are drawn is presented; fourth, the findings from the study in relation to structural challenges are discussed; and finally, we highlight how policy and practice could be modified to improve outcomes for homeless people and consider the lessons learned from the Welsh model for other contexts.

\section{Homelessness policy and prevention in an international context}

There has been a shift in international homelessness policy towards prevention: for example, in Australia (Parsell and Marston, 2012), the US (Culhane et al., 2011), the UK (Clapham et al., 2009), Canada (Crane et al., 2006), Ireland (Maher and Allen, 2014) and Germany (Busch-Geertsema and Fitzpatrick, 2008). There is consensus that homelessness should be prevented (Shinn et al., 2001) as it reflects badly on a society which permits it, damages individuals and communities, and there are significant costs involved in 'curing' it (Mackie, 2014). Although there is less agreement about what interventions take place at each level, there is broad agreement that homelessness prevention can be focused on primary, secondary and tertiary prevention (Busch-Geertsema and Fitzpatrick, 2008).

Targeting the structural causes of homelessness - for example, availability of accommodation, affordability, poverty and income - is generally believed to fall within the remit of primary prevention activities (Busch-Geertsema and Fitzpatrick, 2008) and arguably the most effective prevention occurs at this level (Maher and Allen, 2014). Here increasing housing supply and reducing socio-economic disadvantage would be panaceas (see the review article in this themed section for a detailed discussion of prevention measures: Ahmed and Madoc-Jones, 2019). However, neo-liberalism - the policy model of the UK since the 1980s - favouring free market capitalism, reducing government spending, regulation and public ownership, fiscal austerity and privatisation has been influential in shaping housing systems and has led to a focus on the market, promotion of 
owner-occupation as the main tenure and the residualisation of social housing e.g. through right to buy (Jones, 2010). In the UK, since the 1970s spending on welfare has been linked to a growing economic crisis and presented as a major obstacle to global competitiveness (Forrest and Hirayama, 2009). The subsequent neo-liberal welfare regime - with laissez-faire policies, focused on individual reflexivity and market rationality - has then emphasised agency over structure and positioned homelessness as a result of poor decisions (Farrugia and Gerrard, 2016). Less attention has then been given to the structural causes of homelessness (Parsell and Marston, 2012) such as the mass sale of council housing (Fitzpatrick et al., 2000) through the 'Right to Buy' scheme introduced by the 1980 Housing Act. As a result of this neo-liberal informed scheme (Carr and Hunter, 2008) house price inflation followed, along with higher rents in the private rented sector.

Historically statutory rights to settled housing have been limited to the UK (Fitzpatrick et al., 2012) and discharged by local authorities who adopted the definition of homelessness enshrined in the 1977 Housing (Homeless Persons) Act: an applicant is homeless when there is no accommodation for them to occupy or it is unreasonable for them to occupy it (due to poor conditions). This Act was subsequently amended by the Housing Act 1996 so that a statutory duty to rehouse only those households deemed to be in priority need and unintentionally homeless and for whom a local connection existed. Activities to prevent homelessness may have been undertaken in some instances, but this was ambiguous and occurred outside of the legislation (Ahmed et al., 2018) and had variable application (Mackie, 2015). In this way, over the last few decades, the focus of legislation has been on intervention rather than prevention, and eligibility for any sort of service provision has been subject to an inflexible assessment process (Connell et al., 2017). Carr and Hunter (2008) suggest policy has been slow to change because a focus on the 'technical' elements of the legislation - for example, eligibility testing - allowed successive neo-liberal inspired Governments to present themselves as adopting a depoliticised approach to tackling homelessness.

More recently, as stated, Part 2 of the Housing Act (Wales) 2014, reoriented homelessness policy in Wales towards prevention and aimed to ensure that help is available for everyone who is at risk of homelessness or is homeless and that early interventions should take place to prevent crises. In Wales, although they have needed to form coalitions, Welsh Governments have always been Labour led. More importantly perhaps, it is widely considered that, much like Scottish Governments, they have been more sympathetic to social democratic principles, than their counterpart New Labour (1997-2010) or Conservative led (2010 -present) Governments in England (Williams, 2007). As a result, there are 'vastly different interpretations of the causes and solutions to poverty and inequality, as well as the appropriate role and size of the state' in Wales and England (McKee et al., 2017: 68). Welsh politics is characterised by a concern for co-operation rather than competition and support for the public sector as opposed to neo-liberalism (Williams, 2007: 14). Accordingly, a more inclusive approach to those experiencing poverty and social exclusion exists in Wales (Brewster and Jones, 2018) and different housing policies have been pursued. For example, there has been less of a move away from social housing and towards the market than found in England; less deregulation of the private rented sector; and Right to Buy schemes (which reduce the supply of social housing stock) have been abolished.

Policy implementation involves a complex dynamic change process over time (Sabatier, 1986; Schofield, 2002) and is 'characterized by the actions of multiple levels 
of agencies, institutions, organisations and their actors and is influenced by context throughout' (De Groff and Cargo, 2009: 48). Significantly, Wales is a small, sub-national government 'operating under externally-imposed institutional and financial constraints' (Connell et al., 2017: 3). While Welsh Government has devolved powers over housing policy in Wales, no such powers exist in relation to other key areas likely to impact on levels of homelessness such as economic and welfare policy. Although very recently Welsh Government has become responsible for some of the taxes paid in Wales (from April 2018), for the most part it has not been able to raise taxes independently. Significantly, spending on homelessness services has been through grants to local authorities which are determined by the UK Treasury on the basis of proportional equivalent spending to that in England (Connell et al., 2017).

The UK Government's approach to managing the Global Financial Crisis of 2008 has been to introduce austerity and reduce public expenditure. This has impacted on local government and third sector funding and on benefits for working age people which, in addition to being frozen, are now increasingly 'conditional' on behaviour. If compliance with particular conditions is not met, then 'sanctions' are imposed which suspend or remove eligibility for benefits (Watts and Fitzpatrick, 2018). This context has led some scholars to question whether preventative homelessness policy can be successfully realised in Wales (Fitzpatrick and Pawson, 2016) and to express concerns about the potential impacts of resource constraint and austerity on legislative implementation (Mackie, 2015). Structural constraints could therefore impose limits to how far the Welsh Government is able to realise its housing priorities.

\section{Methodology}

Data underpinning this article are drawn from a Welsh Government commissioned longitudinal post-implementation evaluation of the processes and impacts of the Act which began in April 2016 with the final report being published in July 2018. The evaluation itself involved qualitative and quantitative research methodologies encompassing: quantitative analysis of secondary data (2015-16 and 2016-17) ${ }^{1}$; survey and review of twenty-two local authorities (first wave: June-August 2016/ second wave: August - October 2017). The purpose of the local authority surveys was to gather detailed qualitative and quantitative information relating to the different stages outlined in the Act. The second wave survey aimed specifically to understand changes in the experiences of the local authority housing team in the year since they completed the first wave survey; consultation with fifteen national stakeholders (October-November 2016); these stakeholders were identified by the project steering group as being significant in shaping the Act and were in a position to provide an important perspective regarding its ethos, implementation and impact ${ }^{2}$.

Six case study local authorities were also selected on the basis of geography: urban/ rural/coastal and north/mid/south Wales and whether housing stock had been retained by the local authority or transferred to a registered social landlord (RSL) $)^{3}$. Consultation was undertaken with service users and service providers in each of the case study areas to understand the experience and delivery of services. A longitudinal qualitative methodology was utilised with service users. The first wave of the research took place in October 2016-January 2017 and was undertaken with people who presented to homelessness 
services in each of the case study areas. In total, 154 interviews were conducted across the six local authority areas in the first wave and the sample was influenced by the people who presented as homeless or were receiving assistance from the local authorities during the time of the fieldwork. After the completion of a wave 1 interview, participants were asked for their permission to be re-contacted in six to eight months. Wave 2 of the research with service users took place in June-July 2017. There was significant attrition and fiftyseven service users were interviewed. The majority of service users were single person households (49 per cent in wave 1; 54 per cent in wave 2) and all were over the age of eighteen.

Consultations with a variety of service providers were undertaken representing the statutory sector, RSLs and the third sector across the six case study sites. The research team collected the views and experiences of key stakeholders including heads of service, Supporting People leads, service managers and frontline staff. A total of 148 service providers across a range of sectors and authorities were consulted. Consultations were undertaken between March and June 2017. The data were analysed thematically and organised under the following overarching categories: the impacts and processes of the Act; implementation and administration; partnership working; person-centred practice; vulnerable groups; the private rented sector; and welfare reform and other structural challenges.

In the findings below service users are denoted as SU, service providers as LA, RSL and TS (local authorities, Registered Social Landlords and third sector organisations).

\section{Findings: structural challenges to implementing the legislation}

Whilst comparisons with previous years are problematic, as prevention activities were not recorded, the 2016-17 local authority data return shows that there was an overall increase in the number of recorded cases at each of the main stages of the legislation. Overall 5,718 households were prevented from becoming homeless in March 2016 - April 2017. In the same period, 4,500 were relieved, and 1,674 received a positive discharge. Of the people engaging with local authorities and interviewed in the first wave of the fieldwork, only thirty-one were threatened with homelessness, while ninety-eight were already homeless, demonstrating that people still usually present at the point of crisis. However, the proportion of prevention cases that were successful was 62 per cent in 2016-17, demonstrating that 'positive outcomes can be achieved even in the face of unhelpful structural trends' (Busch-Geertsema and Fitzpatrick, 2008: 90).

The UK Government implemented significant reforms through the Welfare Reform Act 2012 and Welfare and Work Act 2016. This has affected welfare benefits and tax credits and further cuts are yet to be implemented. The Equality and Human Rights Commission estimates that households in Wales will lose 1.5 per cent of their net income from reforms implemented since 2010 and the biggest impact will be felt by those on the lowest incomes (Senedd Research, 2019). Unsurprisingly, austerity and ongoing budget cuts were identified as challenges to the successful implementation of the Act. In particular, service provider participants across sectors recounted many examples of third sector support services which had closed as a result of funding cuts. This was also reported by several respondents to the local authority survey:

'Third sector funding has been cut and as such partners have also had to cut their services'. 
It was widely perceived by research participants that budget cuts and austerity, originating from UK Government policy created challenges to the Act's implementation as such policy was outside the control of the Welsh Government:

I think the challenge that we've got in Wales is that things like benefit cuts ... are all things that come from Westminster and that the Welsh Government, well certainly Welsh authorities haven't got so much control over'. (TS)

In 2015-16, the twenty-two Wales local authorities spent $£ 27 \mathrm{~m}$ on homelessness and housing advice, compared to $£ 33 \mathrm{~m}$ in 2009-10. However, taking account of inflation, this is a reduction of 26.3 per cent (Wales Audit Office, 2018). To assist with the implementation of the 2014 Act the Welsh Government provided local authorities with grant funding (transitional funding) of approximately $£ 11.5$ million between 2015-16 and 2017-18, a further $£ 6$ million per year was allocated in 2018-19 and 2019-20. National stakeholders, respondents to the local authority survey and service provider participants highlighted the crucial role of transitional funding in implementing the Act and expressed significant concerns about its gradual reduction and eventual planned removal. Transitional funding was cited as the core mechanism through which changing demand for services had been met by twenty-one of the twenty-two authorities in the survey. While cognisant of the fact that the current funding was by its very nature transitional, service provider participants across sectors and respondents to the local authority survey indicated that there was a need for longer term, sustainable funding to ensure that prevention activities continue to be resourced and the Act successfully implemented. Twelve local authority respondents to the survey reported experiencing significant problems in implementing the legislation in 2016-17 due to limited resources.

Several service providers commented that successful prevention work and tenancy support would have significant ongoing resource implications:

'I think the more the Government want to push forward preventiveness, they have to supply the funding in order to get the agencies on board, otherwise, it's not going to be feasible.' (RSL)

There was a common view that the introduction of Universal Credit (UC), being rolled out across Wales under the Welfare Reform Act, was creating difficulties for people and homelessness service providers. UC replaces the previous benefit payment process so that a single monthly payment is then paid directly to the claimants. (This includes any rental element which would previously have been paid direct to landlords.) The rollout of UC is linked to higher incidences of rent arrears and Welsh Government has commissioned additional research to examine how the administration of UC could be causing rent arrears (Senedd Research, 2019). One third sector service provider described their experience of working with service users in receipt of UC:

'We've had three people so far. All of them have [messed] up big style. They only get 152 quid for the month or these people did. It's gone. The end of that month is a long way away.' (TS)

The perception that service users would struggle to manage welfare benefits received via UC was common. It was also anticipated that budgeting difficulties would lead to 
service users accruing rent arrears, a common factor leading to homelessness. Whilst there was goodwill and empathic practices to support tenants in receipt of UC who were not adept at managing their finances, the lengths that service providers could go to were considered to be finite and time-bound. One RSL service provider explained that their organisation's position was to try to help those in receipt of UC who accrued rent arrears, but there were concerns about their capacity to support increasing numbers of people:

'When more and more become UC claimants you can't be so nice to them and try and hold their hand through it.' (RSL)

The move to UC was considered to be particularly problematic in relation to accessing the private rented sector (PRS). The payment of UC directly to claimants was considered to act as a further deterrent to private landlords accepting people in receipt of benefits:

'Well, they've changed the system now, isn't it? They pay the person, because I do know a lot of people who have actually spent, even for their housing association property, the rent's come to them and they've spent it, so landlords don't particularly... They just don't want people on housing benefit.' (SU)

In addition, time delays in the UC system with payments taking six to eight weeks from the initial claim were expected to create further difficulties as it was felt that the majority of private landlords would be unable to accommodate this. Wider evidence confirms that waiting times for the first payment of UC are significantly longer than for previous 'legacy benefits' (Senedd Research, 2019).

The widespread implementation of UC was therefore described as likely to 'fail a lot of people'. Significantly, a number of service providers across sectors and case study areas felt that UC would lead to increases in homelessness:

'The majority of people outside of these services then, they're going to struggle. Then they become homeless because of rent arears and we're going to be affected because there are no hostel rooms anymore. It's constantly a big thing where homelessness is increasing.' (TS).

It was also acknowledged that welfare conditionality and sanctioning, specifically in relation to people who are homeless or at risk of homelessness imposed further hardship on people and increased the risk of homelessness:

'We shouldn't forget that The Welfare Reform Act has really thrown a big bucket of cold, dirty water on it, with people getting sanctioned and all sorts of different things and forcing them into crisis. It's just made it a lot worse, hasn't it?' (RSL)

Shortage of accommodation is an accepted structural dimension of homelessness and it is also accepted that addressing housing supply and poverty is necessary to achieve primary homelessness prevention (Parsell and Marston, 2012). The lack of social housing provision across Wales was widely acknowledged to be a fundamental obstacle to countering homelessness as 'social housing, as everywhere, is under great demand, 
in short supply' (TS). It is estimated that there are over 65, 000 households on local authority waiting lists in Wales ${ }^{4}$. Over a third of the service users expressed frustration at the lack of social housing and the barriers to entering the PRS. Several people reported that they had felt supported by local authority Housing Solutions staff but ultimately, because there was a shortage of housing in their area, that there was a limit to the extent to which they could actually be helped:

'[T]hey haven't got enough houses to go round. Let's put it that way. That's obvious. Nobody can do anything about that. Well, okay, the government could do a lot about it. Why not do what they done in the '60s and '70s and start building?' (SU)

In both waves of the fieldwork the majority of service users indicated a preference for social housing. Some local authority service providers considered the PRS was not an ideal long-term solution to resolving homelessness since it was unaffordable for many people. As one respondent to the local authority survey commented:

'Rents within the PRS are increasing and due to the high demand, more landlords are refusing to take tenants on benefits'.

Service providers also suggested that service users were reluctant to enter the PRS for a range of reasons including: previous poor experiences of the sector; undesirable or inconvenient locations of properties; poor quality of accommodation; high rents; the short-term nature of tenancies; and insecurity and anticipated eviction, as the following excerpt illustrates:

'Private renting sector is only short-term they see it as, you don't get the quality, you don't get the rights that perhaps you would get in your social housing'. (LA)

Indeed, a significant number of service users were facing homelessness due to tenancies ending or having experienced difficulties in the PRS. However, this varied somewhat by area depending on the availability of affordable accommodation. A further challenged cited by service providers was the lack of accommodation for single people. One service user stated:

'Oh, it's impossible, it really is. I don't know how people manage to do it. I think unless you know a landlord, or your parents know someone, I don't think it's possible. I really don't. You'd have to be very lucky.' (SU)

In some areas, the Local Housing Allowance (LHA) - the maximum amount of rent that would be paid by the state - created barriers to accessing affordable accommodation. This was due to the LHA cap being lower than the average rents and so there was a gap in terms of local need and affordable housing stock:

I think affordability is one of the main challenges for us as a social outlet at the moment.... So, in some of our areas ... the two-bedroomed properties are out of reach of some people on the housing register, even with benefits because the benefit cap is under the weekly rent'. (RSL) 


\section{Discussion}

It is evident that the Act has fundamentally changed the way that Local Authority Housing Solutions Teams work with people who are homeless/threatened with homelessness in Wales (Shelter Cymru, 2016a; Ahmed et al., 2017, 2018). Previously outside of the legislation, prevention is now at the core of the Act, and there is increased flexibility in how local authorities can intervene to address the causes of homelessness. However, evidence to date suggests that there is significant variation in approaches within and between authorities (Shelter Cymru, 2016b; Welsh Audit Office, 2018; Ahmed et al., 2017, 2018).

It is important to note that as the causes of homelessness are partly attributed to structural problems, the solutions to homelessness are also structural. Although the Act and its focus on prevention could be construed as a structural solution to homelessness, issues such as shortage of accommodation, unemployment and poverty, however, lie outside of its remit. Accordingly, whilst it is clear that local authorities are preventing homelessness on an individual basis and reacting to homelessness and the problems it causes, the structural causes of homelessness remain unaddressed. Increased demand for services since the introduction of the Act is also challenging, compounded by a lack of available accommodation for people to move people to. This impacts on local authorities' ability to effectively prevent and relieve homelessness.

The introduction of $U C$, and Welfare Reform more generally, runs counter to the person-centred ethos of the Act. Welfare Reform has had a disproportionate effect in several areas of Wales as a result of industrial decline over time. The reduction in the level of benefit payments compromises people's ability to pay for private rented accommodation and also acts as a deterrent to private landlords letting properties to people in receipt of benefits. A shortage of some particular forms of accommodation - particularly for single occupancy - across the social and private rented sector further compromises local authorities' ability to prevent and relieve homelessness.

Arguably the roll out of UC is expected to exacerbate challenges to tacking homelessness. Whilst the Welsh Government has not escaped criticism for not doing enough to mitigate the effects of Welfare Reform so far (McKee et al., 2017), the situation is likely to worsen in the next few years as the Welsh Government does not have the resources to mitigate future cuts to benefits (Senedd Research, 2019). On an individual level, often people do not have the experience or skills to budget/manage money and increases in debt/ rent arrears are likely to lead to eviction and increase homelessness (Ahmed et al., 2018). Further, the complexity of the welfare system is likely to confuse people and also potentially negatively impact on their income levels. Moreover, the deficit between benefit payments and rent levels will also impact on affordability in the PRS.

In the context that neo-liberalism, austerity and devolution are becoming global trends (MacKinnon, 2015; Taylor-Gooby et al., 2018) the analysis presented is relevant for other subnational contexts where governments are seeking to develop policy to address homelessness. In different contexts, different challenges to the ones faced in Wales will arise and reflect the particular institutional and legal arrangements between tiers of government that exist. However, as Connell et al. (2017: 2) indicate, subnational governments will have 'tools' at their disposal that can be leveraged to promote their policy objectives. Not least amongst these in Wales, as our findings show, was the ability to assist with the implementation of the 2014 Act with grant funding (transitional funding). Longer term leverage of the tools of government may become necessary in situations 
where policy implementation stagnates, and a gap opens up between subnational government-set objectives and the organisations which implement them (Rosli and Rosli, 2014). Such continuing leverage is evident in Wales where Welsh Government, for example, has established an Independent Affordable Housing Review to examine the potential for social housing provision to increase to meet the demand for affordable housing in Wales (Wallace, 2019). A significant consideration for other contexts is that universal policies cost money (Williams, 2007). Adding stages to the existing processes for managing homelessness will not necessarily be resource neutral (as was the original intention of the Welsh legislation's introduction). Amid funding cuts in some Welsh local authority areas since 2010 of nearly 25 per cent, it is not automatically the case that local authorities in Wales have been adequately resourced to fulfil their responsibilities and implement policy (Gray and Barford, 2018).

Finally, a wide range of shared values embedded within national political cultures can impact upon and influence the nature and outcomes housing system (Fitzpatrick and Stephens, 2014). In Wales preventative housing policies seek to enhance information sharing systems and multiagency working to address homelessness. It is possible, however, that in one context a turn to prevention can underpin a focus on the structural and systemic causes of homelessness. Conversely, in another context such a turn can underpin efforts to close the net of surveillance around a 'problematic group'. Over the past decade, there has been a paradigm shift in the developed world towards homelessness prevention (Mackie, 2015), but preventing homelessness can appeal to a range of political sensitivities. Accordingly, a shift in towards preventing homelessness may not depend on any paradigm shift in thinking about homelessness itself (Mackie, 2014). The political and applied flexibility associated with preventing homelessness can explain why prevention focussed policies have been reported in a range of countries with very different political and economic positions (Mackie, 2014), and why the new system of homelessness prevention enacted in Wales has recently become the template for the English Homelessness Reduction Act 2018. As indicated above, policy implementation involves a complex change process over time and is influenced by the policy interpretive actions of a whole range of actors at multiple subordinate levels of Government, in different agencies, institutions, organisations and contexts (De Groff and Cargo, 2009: 48). It follows that the value base underpinning policy can be crucial in terms of how policies are then experienced

\section{Conclusion}

In the final section we propose a number of actions that the Welsh Government (and others in a similar position wishing to embrace a preventative approach) might undertake to mitigate the kind of structural challenges experienced in Wales. Although significant financial investment has already been made, the Welsh Government needs to continue to provide funding to support local authorities post 2019/20. Funding will be needed to cover staff costs; skills training; and prevention. The Welsh Government should monitor homelessness levels and make adjustments to align resources to those areas where the number of homeless presentations and rough sleeping has increased. Since progress in implementing the legislation is variable across Wales, sharing and embedding of good practice across local authorities is needed and this should be done via the Local Authorities Homelessness Network which includes representatives from each authority. Improved monitoring by local authorities is also needed and IT infrastructures should 
support the monitoring and tracking of individual cases (rather than collecting aggregate data). In addition, keeping full records of reviews and appeals would help to provide a more accurate picture of local authority and service user interpretations of the legislation and allow more accurate monitoring in general.

In order to militate against the impacts of Welfare Reform, local authorities need to be more aware of the impacts of UC and how to manage delays in the system. Learning from authorities who have already implemented UC should be shared again, via the Local Authorities Homelessness Network. Local authorities should also use discretionary housing payments to facilitate homelessness prevention. Budgeting and money management should form part of new tenant training. Each local authority should appoint a Welfare Reform Officer to focus on increasing income and reducing expenditure for service users.

Local authorities should work with RSLs to prevent evictions and increase tenancy sustainability: for example, by conducting joint interviews prior to court hearings. Further, in order to meet homelessness strategies, local authorities should work with RSLs to increase the availability of appropriate accommodation through using Social Housing Grant funds, informed by an evidence base in each local authority area. The Welsh Government should explore how they can support private landlords and private sector tenancies to ensure consistency of services with RSL provision. The use of private rented sector officers and social lettings agencies should be rolled out across authorities and a standardised approach should be adopted by local authorities. In Wales this could also be developed through the Local Authorities Homelessness Network. Local authorities should continue to work with private landlords to provide support financial and other forms of tenancy particularly for tenants with vulnerabilities. More incentives should be in place for private landlords to take welfare claimants, including paying for repairs/rent arrears and using LA contractors to conduct repairs. Local authorities should consider establishing a Landlord Support Service in their area to ensure that they stay in the sector.

\section{Notes}

1 All data is taken from the publicly available Stats Wales website (https://statswales.gov.wales/ Catalogue). All figures used here are for April 2016 - March 2017.

2 Community Housing Cymru; Chartered Institute of Housing Cymru; Cymorth Cymru; Higher Education institution; Homelessness Network; Shelter Cymru (two respondents); Private Landlords Association; Take Notice Project; Welsh Local Government Association; Welsh Government Housing Policy Division (four respondents); Tai Pawb; Chartered Institute of Housing.

3 Additional criteria extrapolated from Stats Wales (2017), including performance based on homelessness successfully prevented (s66) and relieved (s73) also guided selection. Other studies currently being conducted by Shelter Cymru and the Wales Audit Office were also taken into account, although this did not necessarily preclude inclusion.

4 BBC News 27.3.18 Councils/FOI request. Two authorities did not hold any information, so this is an underestimation.

\section{References}

Ahmed, A. and Madoc-Jones, I. (2019) 'Homelessness prevention policy in an international context: The Housing Act (Wales) 2014', Social Policy and Society, doi: 10.1017/S147474641900037X.

Ahmed, A., Jones, K., Gibbons, A., Rogers, M., Wilding, M. and Madoc-Jones, I. (2017) Post-Implementation Evaluation of Part 2 of the Housing Act (Wales) 2014 (Interim Report), Cardiff: Welsh Government. 
Ahmed, A., Jones, K., Gibbons, A., Rogers, M., Wilding, M. and Madoc-Jones, I. (2018) Post-Implementation Evaluation of Part 2 of the Housing Act (Wales) 2014, Cardiff: Welsh Government.

Busch-Geertsema, V. and Fitzpatrick, S. (2008) 'Effective homelessness prevention? Explaining reductions in homelessness in Germany and England', European Journal of Homelessness, 2, 69-95.

Brewster, D. and Jones, R. (2018) 'Distinctly divergent or hanging onto English coat-tails? Drug policy in post-devolution Wales', Criminology and Criminal Justice 19, 3, 364-81.

Carr, H. and Hunter, C. (2008) 'Managing vulnerability: homelessness law and the interplay of the social, the political and the technical', Journal of Social Welfare and Family Law, 30, 4, 293-307.

Clapham, D. F., Mackie, P. K. and Pritchard, J. (2009) 'Homelessness policy in Wales: which path will it take?', in S. Fitzpatrick, D. Quilgars and N. Pleace (eds.), Homelessness in the UK: Problems and Solutions, Coventry: Chartered Institute of Housing, 125-40.

Connell, A., Martin, S. and St Denny, E. (2017) 'How can subnational governments deliver their policy objectives in the age of austerity? Reshaping homelessness policy in Wales', The Political Quarterly, 88, 3, 443-51.

Crane, M., Warnes, A. M. and Fu, R. (2006) 'Developing homelessness prevention practice: combining research evidence and professional knowledge', Health and Social Care in the Community, 14, 2, 156-66.

Culhane, D. P., Metraux, S. and Byrne, T. (2011) 'A prevention-centred approach to homelessness assistance: a paradigm shift?', Housing Policy Debate, 21, 2, 295-315.

De Groff, A. and Cargo, M. (2009) 'Policy implementation: implications for evaluation', in J. M. Ottoson and P. Hawe (eds.), Knowledge Utilization, Diffusion, Implementation, Transfer, and Translation: Implications for Evaluation, New Directions for Evaluation, 124, 47-60.

Farrugia, D. and Gerrard, J. (2016) 'Academic knowledge and contemporary poverty: the politics of homelessness research', Sociology, 50, 2, 267-84.

Fitzpatrick, S., Kemp, P. and Klinker, S. (2000) Single Homelessness: An Overview of Research in Britain, Bristol: Policy Press.

Fitzpatrick, S. (2005) 'Explaining homelessness: a critical realist perspective', Housing, Theory and Society, $22,1,1-17$.

Fitzpatrick, S. and Stephens, M. (2014) 'Welfare regimes, social values and homelessness: comparing responses to marginalised in six European countries', Housing Studies, 29, 2, 215-34.

Fitzpatrick, S. and Pawson, H. (2016) 'Fifty years since Cathy Come Home: critical reflections on the UK homelessness safety net', International Journal of Housing Policy, 16, 4, 543-55.

Fitzpatrick, S., Johnsen, S. and Watts, B. (2012) International Homelessness Policy Review: A Report to Inform the Review of Homelessness Legislation in Wales, Cardiff: Welsh Government.

Forrest, R. and Hirayama, Y. (2009) 'The uneven impacts of neoliberalism on housing opportunities', International Journal of Urban and Regional Research, 33, 4, 998-1013.

Gray, M. and Barford, A. (2018) 'The depths of the cuts: the uneven geography of local government austerity', Cambridge Journal of Regions, Economy and Society, 11, 3, 541-63.

Jones, B. (2010) 'Slum clearance, privatization and residualization: the practices and politics of council housing in mid-twentieth-century England', Twentieth Century British History, 21, 4, 3510-539.

Mackie, P. (2014) 'The Welsh homelessness legislation review: delivering universal access to appropriate assistance?', Contemporary Wales, 27, 1, 1-20.

Mackie, P. (2015) 'Homelessness prevention and the Welsh legal duty: lessons for international policies', Housing Studies, 30, 1, 40-50.

MacKinnon, D. (2015) 'Devolution, state restructuring and policy divergence in the UK', The Geographical Journal, 181, 1, 47-56.

Maher, C. and Allen, M. (2014) 'What is preventing us from preventing homelessness? A review of the Irish National Preventative Strategy', European Journal of Homelessness, 8, 2, 119-35.

McKee, K., Muir, J. and Moore, T. (2017) 'Housing policy in the UK: the importance of spatial nuance', Housing Studies, 32, 1, 60-72.

Neale, J. (1997) 'Homelessness and theory reconsidered', Housing Studies 12, 1, 47-61. 
Parsell, C. and Marston, G. (2012) 'Beyond the 'at risk' individual: housing and the eradication of poverty to prevent homelessness', Australian Journal of Administration, 71, 1, 33-44.

Pleace, N. (2000) 'The new consensus, the old consensus, and the provision of services for people sleeping rough', Housing Studies 15, 4, 581-94.

Rosli. A. and Rosli. F. (2014) 'Explaining the gap between policy aspirations and implementation: the case of university knowledge transfer policy in the United Kingdom', CIMR Working Paper Series, Working Paper No 20, Birkbeck University of London.

Sabatier, P. (1986) 'Top-down and bottom-up approaches to implementation research: a critical analysis and suggested synthesis', Journal of Public Policy, 6, 1, 21-48

Schofield, J. (2002) 'A model of learned implementation', Public Administration, 82, 283-308.

Senedd Research (2019) Universal Credit in Wales: Update, National Assembly for Wales, http:// seneddresearch.blog/universal-credit-in-Wales-update [accessed 30.07.2019].

Shelter Cymru (2016a) Accessing and Sustaining Social Tenancies: Exploring Barriers to Homelessness, Swansea: Shelter Cymru.

Shelter Cymru (2016b) Reasonable Steps: Experiences of Homelessness Services Under the Housing (Wales) Act 2014: Swansea, Shelter Cymru.

Shinn, M., Baumohl, J. and Hopper, K. (2001) 'The prevention of homelessness revisited', Analyses of Social Issues and Public Policy, 1, 1, 95-127.

Somerville, P. (2013) 'Understanding homelessness', Housing, Theory and Society 30, 4, 384-415.

Stats Wales (2017) https://statswales.gov.wales/Catalogue/Housing/Homelessness [last accessed 31.03.2018].

Taylor-Gooby, P., Hvinden, B., Mau, S., Leruth, B., Schoyen, M. A. and Gyory, A. (2018) 'Moral economies of the welfare state: a qualitative comparative study', Acta Sociologica, 62, 2, 1-16.

Wales Audit Office (WAO) (2018) How Local Government Manages Demand: Homelessness, Cardiff: WAO, 8 January.

Wallace, J. (2019) 'Understanding wellbeing and devolution in Scotland, Wales and Northern Ireland', in Wellbeing and Devolution, Cham: Palgrave Pivot, 33-43.

Williams, C. (2007) Social Policy for Social Welfare Practice in a Devolved Wales, Birmingham: Venture Press. 